\title{
ADAPTIVE CURRENT CONTROL METHOD FOR HYBRID ACTIVE POWER FILTER
}

\author{
Minh Thuyen Chau*
}

\begin{abstract}
This paper proposes an adaptive current control method for Hybrid Active Power Filter (HAPF). It consists of a fuzzyneural controller, identification and prediction model and cost function. The fuzzy-neural controller parameters are adjusted according to the cost function minimum criteria. For this reason, the proposed control method has a capability on-line control clings to variation of the load harmonic currents. Compared to the single fuzzy logic control method, the proposed control method shows the advantages of better dynamic response, compensation error in steady-state is smaller, able to online control is better and harmonics cancelling is more effective. Simulation and experimental results have demonstrated the effectiveness of the proposed control method.
\end{abstract}

Keywords: hybrid active power filter (HAPF), fuzzy neural controller, reactive power compensation, predictive control, passive power filter, power quality

\section{INTRODUCTION}

In a power system, the presence of harmonic components in the grid is a cause of the problems such as: power losses, voltage distortion, overheating, overloading, etc. In order to solve harmonic problems, the Passive Power Filter (PPF) [1-4] is often used at the point of common coupling. Although, it has a simple structure and is least expensive, the PPF inherits several disadvantages due to resonance, instability, difficulty to improve total harmonic distortion and no capability of on-line compensation, etc. Furthermore, the compensation characteristics of these PPFs are influenced by the source impedance. From here, the Active Power Filter (APF) [5,6] appears to eliminate harmonic current and reactive power compensation; it is often parallel-connected to a non-linear load, which has the capability of online compensation in tracking harmonic current of nonlinear load. Moreover, unlike PPFs, they do not cause harmful resonance with the grid. Nevertheless, it is limited by high cost, low-power capacity and is difficult to use in high-voltage grids. Another solution to cancel harmonic problem is to adopt a hybrid active power filter (HAPF) $[7,8]$. The HAPF is the combination of active power filter and passive power filters. The aim of HAPF design is to reduce APF capacity. Besides, the $\mathrm{HAPF}$ inherits the advantages of $\mathrm{PPF}$ and $\mathrm{APF}$.

Operation effectiveness of HAPF is dependent on the control method. The control methods that have been used for HAPF can be listed as follows: PI, hysteresis, fuzzy, neural network, predictive control methods, etc. The conventional PI control method has many advantages such as simple structure, easy use and simple implementation $[9,10]$. However, the $K_{P}, K_{I}$ parameters are fixed during the whole control process. Therefore, with fast variable nonlinear loads, the dynamic response of the PI controller will not be good. The Hysteresis control is characterized by its simplicity, fast response but its disadvantages depend on a widely varying switching frequency $[11,12]$. With the fuzzy logic control method then it is seen as conceptually easy to understand, flexible, has robust character in the process of controlling and can be combined with conventional control techniques [13-17]. However, the input-output memberships are fixed and cannot be studied during the whole control process, and its parameters depend on experience. If the controller uses neural network [18-20], the result is based on the training algorithm. The neural network controller can learn, but the response is relatively slow; the transient time is large, and the input and output relations are very difficult to express. The predictive control [21] offers the best potential for precise current control, but the implementation can be difficult and complex.

Therefore, this paper proposed a novel control method for HAPF based on the adaptive fuzzy neural model. This method has capability of online control very well. Moreover, it also has many advantages such as minimum compensation error in steady state, harmonic filter efficiency is improved.

\section{TOPOLOGY AND CONTROL STRATEGY OF HAPF}

Topology of the HAPF is presented as shown in Fig. 1, where $U_{\mathrm{s}}$ and $\mathrm{Z}_{\mathrm{S}}$ are the supply voltage and equivalent impedance of the grid. $\mathrm{C}_{\mathrm{F}}, \mathrm{C}_{1}, \mathrm{~L}_{1}, \mathrm{C}_{\mathrm{P}}, \mathrm{L}_{\mathrm{P}}, \mathrm{L}_{0}$ and $\mathrm{C}_{0}$ are the injection capacitor, fundamental resonance capacitor, fundamental resonance inductor, the $\mathrm{PPF}_{\mathrm{S}}$ capacitor and inductor, the output filter inductor and capacitor,

* Faculty of Electrical Engineering, Industrial University of HoChiMinh City, Vietnam, chauminhthuyen@iuh.edu.vn 


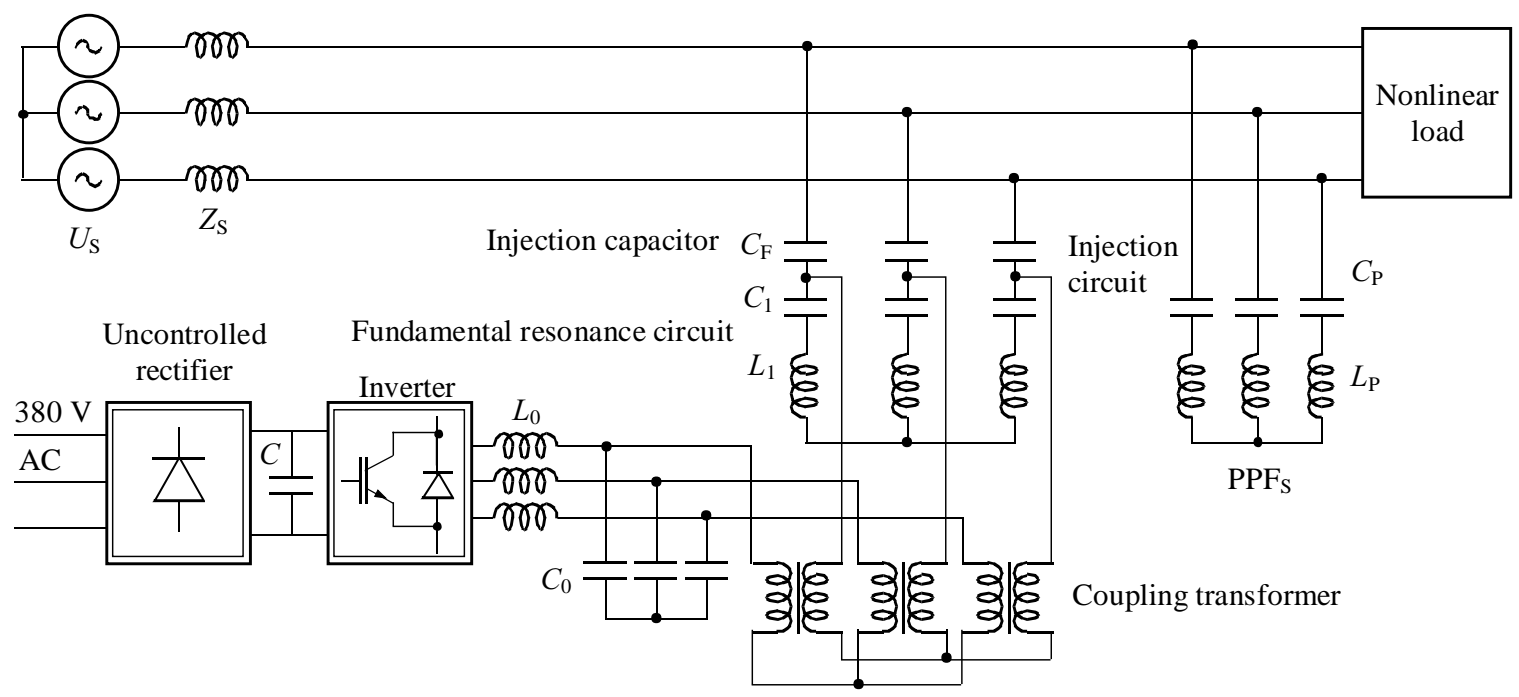

Fig. 1. Topology of the HAPF

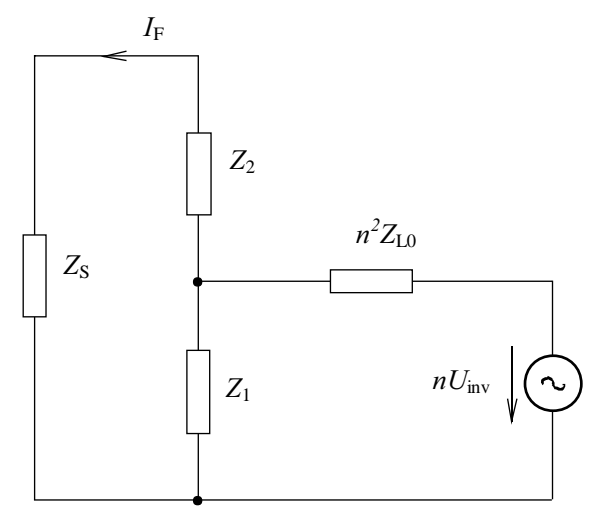

Fig. 2. Single-phase equivalent circuit of HAPF when only the $U_{\text {inv }}$ is considered

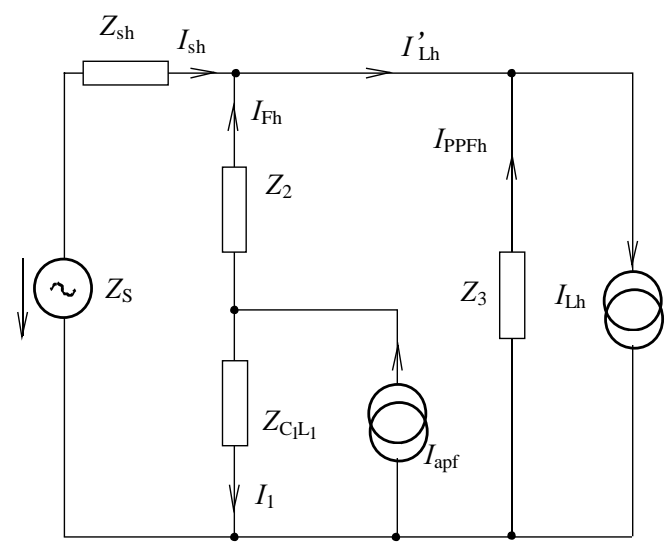

Fig. 3. Single-phase equivalent circuit with the effect of harmonic source

respectively. APF consist of: uncontrolled rectifier, voltage source inverter, an output filter with capacitor $\mathrm{C}_{0}$ and inductor $\mathrm{L}_{0}$ to eliminate switching ripples, coupling transformer and circuit $\mathrm{C}_{\mathrm{F}}-\mathrm{C}_{1}-\mathrm{L}_{1}$. To further decrease the rate of $\mathrm{APF}$, a circuit $\mathrm{C}_{\mathrm{F}}-\mathrm{C}_{1}-\mathrm{L}_{1}$ is added. $\mathrm{C}_{1}$ and $\mathrm{L}_{1}$ tune at the fundamental frequency and then compose with the injection branch $C_{F}$. Nonlinear load is the same as source generated harmonics. Most harmonics suppres- sion and reactive power compensation are implemented by passive power filters. The APF only compensates the residential harmonics. So, the power rating of APF is reduced.

When only considering the response of the controlled voltage source $U_{\text {inv }}$, the voltage source $U_{\mathrm{s}}$ and the load harmonic current $\mathrm{I}_{\mathrm{L}}$ after through PPFs are both set to zero. The single-phase equivalent circuit of HAPF when only the controlled voltage source $\mathrm{U}_{\mathrm{inv}}$ is considered is shown as in Fig. 2, where $Z_{3}=Z_{\mathrm{PPFs}}=\left(Z_{\mathrm{CP}_{\mathrm{P}}}+\right.$ $\left.Z_{L_{\mathrm{P} 1}}\right) /\left(Z_{C_{\mathrm{P} 2}}+Z_{L_{\mathrm{P} 2}}\right) ; Z_{2}=Z_{\mathrm{CF}} ; Z_{1}=Z_{\mathrm{L} 1 \mathrm{C} 1} / n^{2} Z_{\mathrm{C} 0}$.

From Fig. 2, supposing the transfer function from compensation harmonic current $I_{F}$ to inverter output voltage $U_{\text {inv }}$ is $G_{\text {out }}$, then

$$
G_{\text {out }}=\frac{\mathrm{I}_{\mathrm{F}}}{U_{\mathrm{inv}}}=\frac{n Z_{1}}{\left(Z_{1}+Z_{2}+Z_{\mathrm{s}}\right)\left(Z_{0}+Z_{1}\right)-Z_{1}^{2}} .
$$

Single-phase equivalent circuit with the effect of harmonic source is shown in Fig. 3. According to Fig. 3, the following equations can be established

$$
\begin{aligned}
& I_{\mathrm{sh}}=I_{\mathrm{Lh}}^{\prime}-I_{\mathrm{Fh}}, \\
& I_{1}=I_{\mathrm{apf}}-I_{\mathrm{Fh}}, \\
& I_{\mathrm{Lh}}^{\prime}=I_{\mathrm{Lh}}-I_{\mathrm{PPFh}}, \\
& I_{\mathrm{sh}} Z_{\mathrm{sh}}-I_{\mathrm{PPFh}} Z_{3}=U_{\mathrm{sh}}, \\
& I_{\mathrm{Fh}} Z_{2}-I_{\mathrm{PPFh}} Z_{3}=I_{1} Z_{\mathrm{C}_{1} \mathrm{~L}_{1}} .
\end{aligned}
$$

From (2) we can see that: if we can achieve the control goal $I_{\mathrm{Fh}}=I_{\mathrm{Lh}}^{\prime}$ then the following goal can be obtained $I_{\mathrm{sh}}=0$. With $I_{\mathrm{apf}}=K I_{\mathrm{Lh}}$ is output current of the APF [13], this is the best control strategy of the HAPF. From (2), $I_{\text {sh }}$ can be calculated as

$$
I_{\mathrm{sh}}=\frac{\left(Z_{2}+Z_{\mathrm{C}_{1} \mathrm{~L}_{1}}-K Z_{\mathrm{C}_{1} \mathrm{~L}_{1}}\right) Z_{3} I_{\mathrm{Lh}}}{\left(Z_{2}+Z_{\mathrm{C}_{1} \mathrm{~L}_{1}}\right)\left(Z_{3}+Z_{\mathrm{sh}}\right)+Z_{3} Z_{\mathrm{sh}}} .
$$




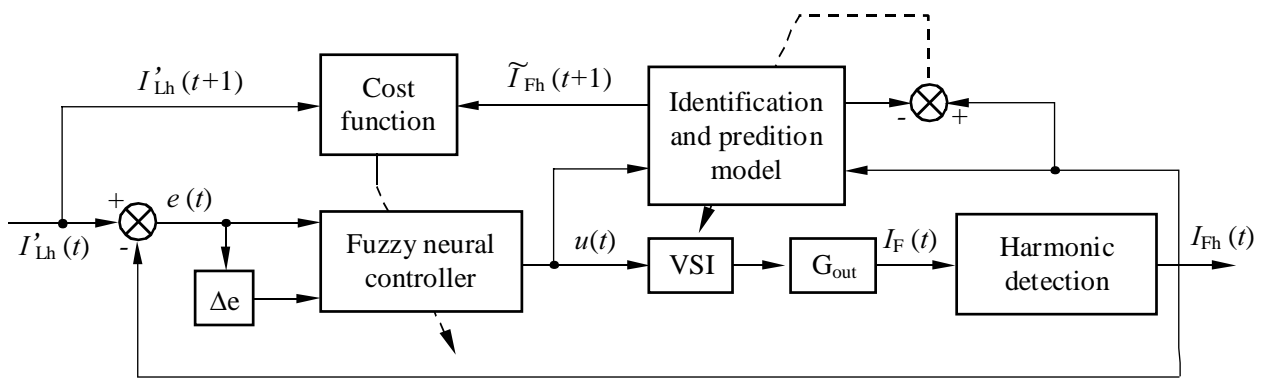

Fig. 4. Proposed control method scheme for HAPF

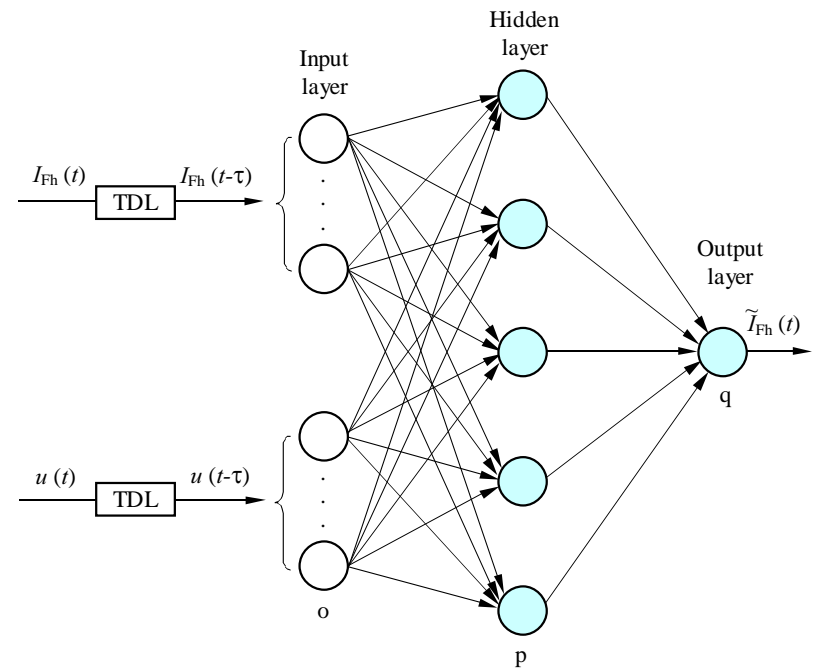

Fig. 5. Neural network structure

Equation (3) indicates that it is possible to eliminate the influence of the load harmonic current and source harmonic current as low as possible if $K$ is large enough. $K$ is controlled gain.

\section{PROPOSED CONTROL METHOD FOR HAPF}

The proposed control method scheme for HAPF is shown in Fig. 4. It consists of three main parts: fuzzyneural controller, identification and prediction model and the cost function. The purpose of the identification and prediction model and cost function is to find a set of optimal parameters for the fuzzy-neural controller. Therefore, the fuzzy-neural controller parameters are adjusted according to the cost function minimum criterion. For this reason, the proposed control method has online control capability clings to variation of the harmonic currents.

The inputs of the controller are $e(t)$ and $\Delta e(t)$

$$
\begin{aligned}
e(t) & =I_{\mathrm{Lh}}^{\prime}(t)-I_{\mathrm{Fh}}(t), \\
\Delta e(t) & =e(t)-e(t-1) .
\end{aligned}
$$

\subsection{Identification and prediction model}

The identification and prediction model are used to identify the non-linear model of APF and predict an output value. The cost function $J$ task is to ensure a minimum error between reference value $I_{\mathrm{Lh}}^{\prime}(t+1)$ and the predicted output value from identification and prediction model. Here, the idea of updating parameters of the fuzzy-neural controller is using the prediction neural network model. The inputs and outputs of HAPF are inputs of neural network; the output of the neural network model is $\tilde{I}_{\mathrm{Fh}}(t)$. An error is formed between the response of the neural network $\tilde{I}_{\mathrm{Fh}}(t)$ and the HAPF model $I_{\mathrm{Fh}}(t)$. This error is then used to update the weights of the neural network model through gradient descent method. This process is repeated until the error is reduced to an acceptable value. The output of the trained neural network model is used as the predicted output of the APF model.

The neural network model used here is a three-layer feed-forward neural network with a time-delayed structure, with a hyperbolic tangent activation function in the hidden layer and a linear activation function in the output layer. The structure of neural network is shown in Fig. 5. The inputs to this neural network consist of $\mathrm{u}(\mathrm{t})$ and $I_{\mathrm{Fh}}(t)$ with their corresponding delay nodes $u(t-\tau)$ and $I_{\mathrm{Fh}}(t-\tau)$.

The equations for this neural network model are

$$
\tilde{I}_{\mathrm{Fh}}(t)=\sum_{p=1}^{\text {hid }} w_{p q} f_{p}\left(\operatorname{net}_{p}(t)\right)+b_{q}
$$

$$
\operatorname{net}_{p}(t)=\sum_{o=1}^{n_{u}} w_{p, o} u(t-\tau)+\sum_{o=1}^{n_{I_{\mathrm{Fh}}}} w_{p, n_{u}+o} I_{\mathrm{Fh}}(t-\tau)+b_{p}
$$

where $f_{p}$ is the transfer function of the hidden neural $p$, $w_{p q}$ and $b_{q}$ are the weights and the bias of the hidden to output layer, $w_{p, o}$ and $b_{p}$ are the weights and the bias of the input to hidden layer, and $\operatorname{net}_{p}(t)$ is the summation of all products between inputs and input to hidden weights in the input layer.

From (4), the predict future output value of APF from the current time $(t)$ to future time $(t+1)$ can be written as

$$
\tilde{I}_{\mathrm{Fh}}(t+1)=\sum_{p=1}^{\mathrm{hid}} w_{p q} f_{p}\left(\operatorname{net}_{p}(t+1)\right)+b_{q} .
$$

\subsection{Fuzzy-neural controller parameters online regulation}

Fuzzy-neural controller structure is shown as in Fig. 6. Its four layers are: input, fuzzy, rules and neural network layers. 


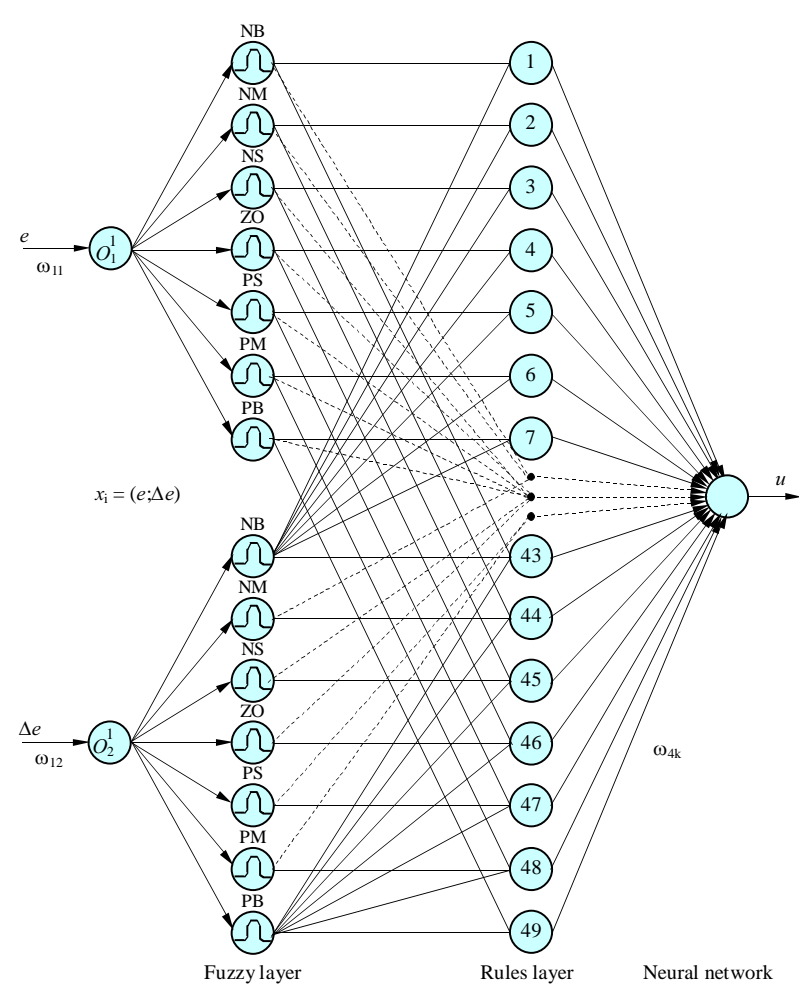

Fig. 6. Fuzzy-neural controller structure

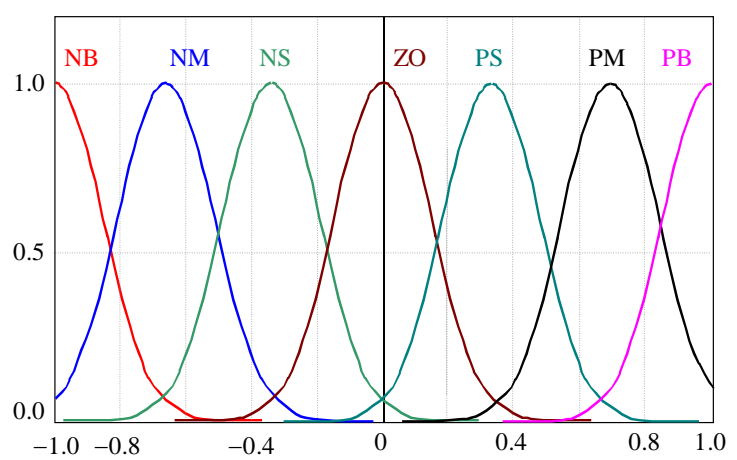

Fig. 7. Membership functions of the fuzzy layer

- Nodes at input layer are input nodes.

$$
\begin{array}{ll}
O_{1}^{1}=e \omega_{1 i}, & i=1,2 \\
O_{2}^{1}=\Delta e \omega_{1 i}, & i=1,2
\end{array}
$$

where $\omega_{1 i}$ are connecting weights,

- Nodes at fuzzy layer are membership nodes. Each input has seven fuzzy linguistic variables which are: Negative Big (NB), Negative Medium (NM), Negative Small (NS), Zero (ZO), Positive Small (PS), Positive Medium (PM) and Positive Big (PB). Membership functions of the fuzzy layer are shown in Fig. 7. With the use of Gaussian membership function, the operations performed in this layer are given as

$$
\begin{aligned}
O_{i j}^{\text {fuzzy layer }}=\mu_{A i}^{j}=\exp (- & \left.\frac{\left(O_{i}^{1}-c_{i j}\right)^{2}}{2 \sigma_{i j}^{2}}\right) ; \\
& \quad i=1,2 ; j=1,2, \ldots, 7
\end{aligned}
$$

where $c$ is the mean, $\sigma$ is the standard deviation and $\sigma^{2}$ is the variance,

- Nodes at rules layer, which represents fuzzy logic rules and there are 49 rules.

$$
\begin{aligned}
O_{k}^{\text {rules layer }} & =\prod_{i=1}^{2} \mu_{A i}^{j}, \\
i & =1,2, j=1,2, \ldots, 7, k=1,2, \ldots, 49 .
\end{aligned}
$$

- The neural network layer, the reasoning consequence of a very reasoning rule is synthesized through connecting weights $\omega_{4 k}$.

$$
O_{\text {neural network }}=u=\frac{\sum_{k=1}^{m} O_{k}^{\text {rules layer }} \omega_{4 k}}{\sum_{k=1}^{m} O_{k}^{\text {rules layer }}}, m=49
$$

where $\omega_{4 k}$ are connecting weights.

First, the cost function $J$ is defined as

$$
J=\frac{1}{2} \sum_{i=1}^{n}\left(I_{\mathrm{Lh}}^{\prime}(t+1)-\tilde{I}_{\mathrm{Fh}}(t+1)\right)^{2}
$$

where $n$ is a learning sample number, $I_{\mathrm{Lh}}^{\prime}(t+1)$ is a reference value, $\tilde{I}_{\mathrm{Lh}}^{\prime}(t+1)$ is the predicted output value from identification and prediction model. The backpropagation method is used to change connecting weights and membership function parameters of network. The training ways are given as follows

$$
\begin{aligned}
\omega(t+1) & =\omega(t)-\eta \frac{\partial J}{\partial \omega}+\alpha[\omega(t)-\omega(t-1)], \\
c_{i j}(t+1) & =c_{i j}(t)-\eta \frac{\partial J}{\partial c_{i j}}+\alpha\left[c_{i j}(t)-c_{i j}(t-1)\right], \\
\sigma_{i j}(t+1) & =\sigma_{i j}(t)-\eta \frac{\partial J}{\partial \sigma_{i j}}+\alpha\left[\sigma_{i j}(t)-\sigma_{i j}(t-1)\right]
\end{aligned}
$$

where $\alpha$ is a smoothness factor, $0<\alpha<1$. $\eta$ is a learning rate, $\eta>0$.

The differential coefficients $\frac{\partial J}{\partial \omega}, \frac{\partial J}{\partial c_{i j}}$ and $\frac{\partial J}{\partial \sigma_{i j}}$ are calculated by back-propagation method.

$$
\begin{gathered}
\frac{\partial J}{\partial \omega_{4 k}}=-\left(I_{\mathrm{Lh}}^{\prime}(t+1)-\tilde{I}_{\mathrm{Fh}}(t+1)\right) p p \tilde{I}_{\mathrm{Fh}}(t+1) \omega_{4 k} \\
=-\left(I_{\mathrm{Lh}}^{\prime}(t+1)-\tilde{I}_{\mathrm{Fh}}(t+1)\right) \frac{\partial \tilde{I}_{\mathrm{Fh}}(t+1)}{\partial O_{k}^{\text {rule layer }}} \frac{\partial O_{k}^{\text {rule layer }}}{\partial \omega_{4 k}} \\
=-\left(I_{\mathrm{Lh}}^{\prime}(t+1)-\tilde{I}_{\mathrm{Fh}}(t+1)\right) f^{\prime}\left(O_{k}^{\text {rule layer }}\right) O_{k}^{\text {rule layer }} \\
=\delta_{k}^{4} O_{k}^{\text {rule layer }}
\end{gathered}
$$

with $\delta_{k}^{4}=-\left(I_{\mathrm{Lh}}^{\prime}(t+1)-\tilde{I}_{\mathrm{Fh}}(t+1)\right) f^{\prime}\left(O_{k}^{\text {rule layer }}\right)$.

The adjusted formula of weight $\omega_{4 k}$ can be shown as

$\omega_{4 k}(t+1)=\omega_{4 k}(t)+\eta \delta_{k}^{4} O_{k}^{\text {rules layer }}+\alpha\left[\omega_{4 k}(t)-\omega_{4 k}(t-1)\right]$. 
Table 1. Simulation parameters of HAPF

\begin{tabular}{lccc}
\hline & $L(\mathrm{mH})$ & $C(\mu \mathrm{F})$ & $Q$ \\
\hline Output filter & 0.2 & 60 & \\
$11^{\text {th }}$ turned filter & 1.77 & 49.75 & 50 \\
$13^{\text {th }}$ turned filter & 1.37 & 44.76 & 50 \\
Fundamental resonance circuit & 14.75 & 690 & \\
Injection circuit & & 19.65 & \\
\hline
\end{tabular}

Table 2. Comparison of the THD $\mathrm{i}_{\mathrm{S}}$ in the steady-state of two control methods

\begin{tabular}{lcc}
\hline & \multicolumn{2}{c}{ THD $\mathrm{i}_{\mathrm{S}}(\%)$} \\
\cline { 2 - 3 } & $\begin{array}{c}\text { Before load } \\
\text { is changed }\end{array}$ & $\begin{array}{c}\text { After load } \\
\text { is changed }\end{array}$ \\
\hline $\begin{array}{l}\text { With the single fuzzy } \\
\text { logic control method }\end{array}$ & 3.19 & 4.55 \\
\hline $\begin{array}{l}\text { With the proposed } \\
\text { control method }\end{array}$ & 1.18 & 1.23 \\
\hline
\end{tabular}

Table 3. Comparison of the power factor in the steady-state of two control methods

\begin{tabular}{lcc}
\hline & \multicolumn{2}{c}{$\cos \varphi$} \\
\cline { 2 - 3 } & $0.6 \mathrm{~s} \div 0.7 \mathrm{~s}$ & $0.9 \mathrm{~s} \div 1.0 \mathrm{~s}$ \\
\hline $\begin{array}{l}\text { With the single fuzzy } \\
\text { logic control method }\end{array}$ & 0.957 & 0.952 \\
\hline $\begin{array}{l}\text { With the proposed } \\
\text { control method }\end{array}$ & 0.984 & 0.981 \\
\hline
\end{tabular}

The differential coefficients can be calculated as follows

$$
\begin{aligned}
\frac{\partial J}{\partial c_{i j}} & =\frac{\partial J}{\partial O_{i j}^{\text {fuzzy layer }}} \frac{\partial O_{i j}^{\text {fuzzy layer }}}{\partial c_{i j}} \\
& =\delta_{k}^{\text {fuzzy layer }} \frac{O_{i}^{1}-c_{i j}}{\sigma_{i j}^{2}} O_{i j}^{\text {fuzzy layer }}, \\
\frac{\partial J}{\partial \sigma_{i j}} & =\frac{\partial J}{\partial O_{i j}^{\text {fuzzy layer }} \frac{\partial O_{i j}^{\text {fuzzy layer }}}{\partial \sigma_{i j}}} \\
& =\delta_{k}^{\text {fuzzy layer }} \frac{\left(O_{i}^{1}-c_{i j}\right)^{2}}{\sigma_{i j}^{3}} O_{i j}^{\text {fuzzy layer }}
\end{aligned}
$$

So, $c$ and $\sigma$ of Gaussian function can be updated as follows

$$
\begin{aligned}
c_{i j}(t+1) & =c_{i j}(t)-\eta\left(\delta_{k}^{\text {fuzzy layer }} \frac{O_{i}^{1}-c_{i j}}{\sigma_{i j}^{2}} O_{i j}^{\text {fuzzy layer }}\right) \\
& +\alpha\left[c_{i j}(t)-c_{i j}(t-1)\right], \\
\sigma_{i j}(t+1) & =\sigma_{i j}(t)-\eta\left(\delta_{k}^{\text {fuzzy layer }} \frac{\left(O_{i}^{1}-c_{i j}\right)^{2}}{\sigma_{i j}^{3}} O_{i j}^{\text {fuzzy layer }}\right) \\
& +\alpha\left[\sigma_{i j}(t)-\sigma_{i j}(t-1)\right] .
\end{aligned}
$$

\section{SIMULATION AND EXPERIMENTAL RESULTS}

\subsection{Simulation Results}

Simulation results of a $10 \mathrm{kV}-50 \mathrm{~Hz}$ HAPF system have been made with the MATLAB software. The system parameters are listed in Table 1 . The nonlinear load is established by four harmonic current sources $5^{\text {th }}, 7^{\text {th }}, 11^{\text {th }}$ and $13^{\text {th }}$. PPFs are passive power filters, they are $11^{\text {th }}$ and $13^{\text {th }}$ turned filters. The dc-side voltage is $600 \mathrm{~V}$.

$\mathrm{i}_{\mathrm{L}}(\mathrm{A}), \mathrm{i}_{\mathrm{Lh}}^{\prime}(\mathrm{A}), \mathrm{i}_{\mathrm{Lf}}^{\prime}(\mathrm{A}), \mathrm{i}_{\mathrm{Fh}}(\mathrm{A}), \mathrm{i}_{\mathrm{Ff}}(\mathrm{A}), \mathrm{i}_{\mathrm{S}}(\mathrm{A})$ and error $(\mathrm{A})$ represents the load current, load harmonic current after through the PPFs, fundamental load current after through the PPFs, harmonic compensation current by $\mathrm{APF}$, fundamental compensation current by APF, source current and error of compensation of phase $\mathrm{A}$, respectively. In the time period $t=(0.0 \mathrm{~s} \div 0.2 \mathrm{~s})$, the system is not connected by PPFs and APF, the load current and source current are the same, the Total Harmonic Distortion (THD) of the load current is $11.52 \%$, the power factor is $0.64(\mathrm{lag})$. In the time period $t=(0.2 \mathrm{~s} \div 0.4 \mathrm{~s})$, the system is connected only by PPFs, the amplitude of $\mathrm{i}_{\mathrm{L}}$ is greatly reduced after through the PPFs and they are analysed in two components $i_{\mathrm{Lh}}^{\prime}$ and $i_{\mathrm{Lf}}^{\prime}$.

Figure 8 shows the dynamic response of HAPF when different control methods are used. At $t=0.4 \mathrm{~s}$ the system is connected by APF and PPFs. When the single fuzzy logic control method is used, the error can be reduced to $\pm 15 \mathrm{~A}$ from $\pm 50 \mathrm{~A}$ in $0.05 \mathrm{~s}$ and it almost does not decrease during the process. When the proposed control method is used, the error can be reduced to $\pm 10 \mathrm{~A}$ from $\pm 50 \mathrm{~A}$ in $0.05 \mathrm{~s}(0.4 \mathrm{~s} \div 0.45 \mathrm{~s})$ and then it decreased to $\pm 3 \mathrm{~A}(0.6 \mathrm{~s} \div 0.7 \mathrm{~s})$. At $t=0.7 \mathrm{~s}$, the load current is changed, the THD of load current increases to $15.25 \%$ from $11.52 \%$ by increase amplitude of the $5^{\text {th }}, 7^{\text {th }}$, $11^{\text {th }}$ and $13^{\text {th }}$ harmonic components, the power factor is 0.64 (lag). With the single fuzzy logic control method, the error increases to $\pm 20 \mathrm{~A}$ from $\pm 15 \mathrm{~A}$ and it almost does not decrease during the process. With the proposed control method, the error increases to $\pm 7 \mathrm{~A}$ from $\pm 3 \mathrm{~A}$ and then it can be reduced to $\pm 3 \mathrm{~A}$ in $(0.9 \mathrm{~s} \div 1.0 \mathrm{~s})$. It is obvious that the adjustment time of the proposed method is better than the single fuzzy logic control method.

Table 2 shows a comparison of the THD $i_{s}$ in the steady-state of two control methods. Table 3 shows a comparison of the power factor $\cos \varphi$ in the steady-state of two control methods.

Compared with the single fuzzy logic control method, The simulation results proved that the proposed control method has following advantages: the compensation error in steady-state is smaller, dynamic response time is shorter, ability to filter harmonics is more effective and online control capability is better.

\subsection{EXPERIMENTAL RESULTS}

The experimental results have been made on a $380 \mathrm{~V}-$ $50 \mathrm{~Hz}$ HAPF model in the laboratory. The experimental parameters are given as in Table 4. 

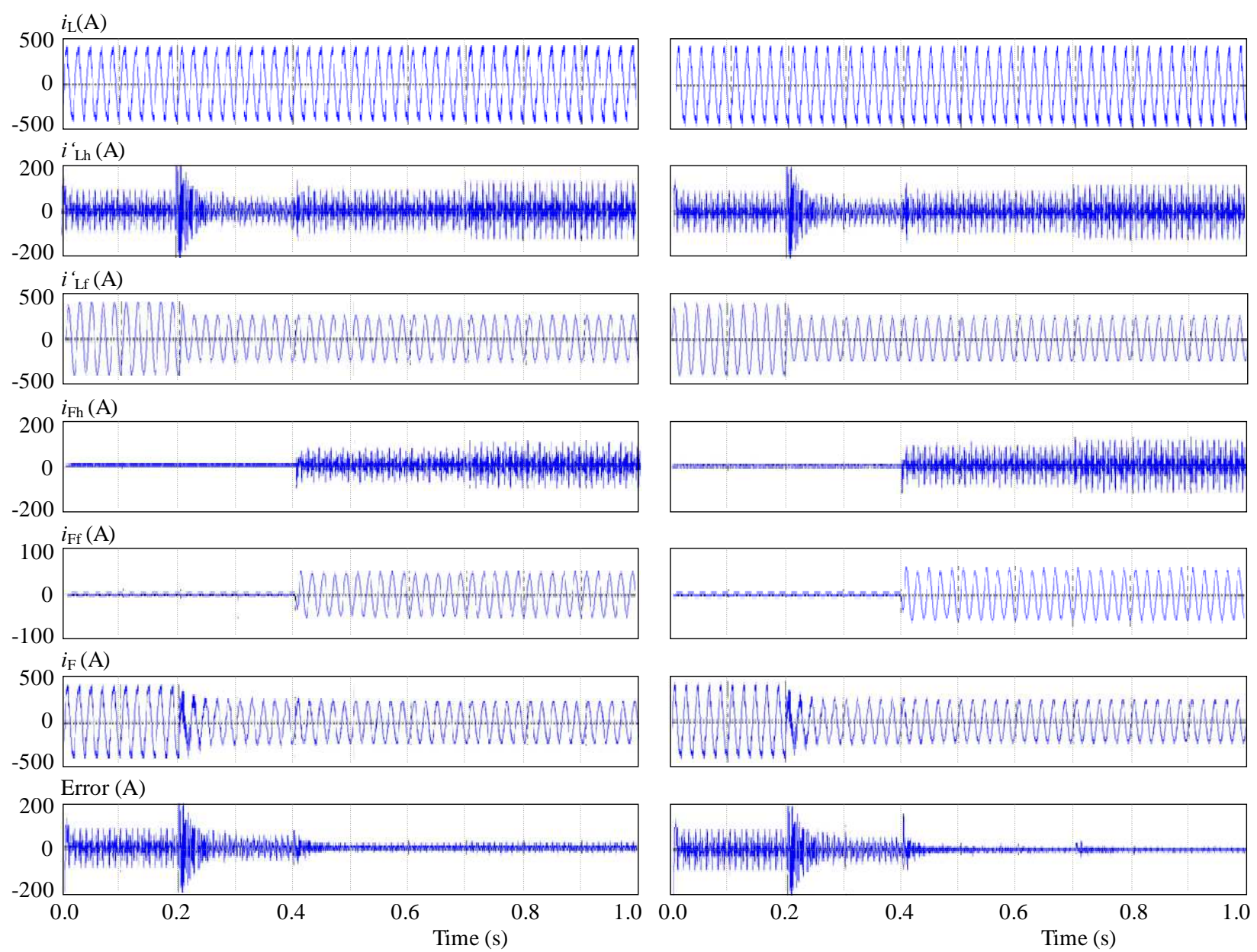

Fig. 8. Dynamic response of HAPF when different control methods are used, (a) - Dynamic response of HAPF with the single fuzzy logic control method, (b) - Dynamic response of HAPF with the proposed control method

Table 4. Experimental parameters of HAPF

\begin{tabular}{cccccccccc}
\hline $\begin{array}{c}\mathrm{C}_{\mathrm{F}} \\
(\mu \mathrm{F})\end{array}$ & $\begin{array}{c}\mathrm{C}_{1} \\
(\mu \mathrm{F})\end{array}$ & $\begin{array}{c}\mathrm{L}_{1} \\
(\mathrm{mH})\end{array}$ & $\begin{array}{c}\mathrm{C}_{11} \\
(\mu \mathrm{F})\end{array}$ & $\begin{array}{c}\mathrm{L}_{11} \\
(\mathrm{mH})\end{array}$ & $\begin{array}{c}\mathrm{C}_{13} \\
(\mu \mathrm{F})\end{array}$ & $\begin{array}{c}\mathrm{L}_{13} \\
(\mathrm{mH})\end{array}$ & $\begin{array}{c}\mathrm{L}_{0} \\
(\mathrm{mH})\end{array}$ & $\begin{array}{c}\mathrm{U}_{\mathrm{dc}} \\
(\mathrm{V})\end{array}$ & $n$ \\
\hline 80 & 349.2 & 29.77 & 49.18 & 1.72 & 44.76 & 1.35 & 0.8 & 650 & $1: 1$ \\
\hline
\end{tabular}

The PPFs are structured of the 11th and 13th order $\mathrm{L}-\mathrm{C}$ harmonic filters. Nonlinear load is established by the three phase controlled rectifier with load is $\mathrm{R}$ and $\mathrm{L}$. A power module IGBT-FF300R12ME4-based VSI with a switching frequency of $10 \mathrm{kHz}$ is used as the main circuit of the APF. A KIT-TMS320F2812 digital signal processor with 32-bit CPU Times, 6.67 ns cycle time of the Texas Instrument company is used to implement the control method. Figure 9 shows the experimental results before the load is changed in steady-state and Fig. 10 shows the experimental results after the load is changed in steadystate.

From the above experimental results we can see that: before and after the load is changed, the THD of the source current with the proposed control method has always been THD is smaller and more stable than the single fuzzy logic control method. This proves that in steady- state, the proposed method is better than the single fuzzy logic method in the harmonics filtering.

\section{CONCLUSION}

A novel adaptive current control method for HAPF was proposed. Compared with the single fuzzy logic control method, this control method demonstrated many advantages such as: error in steady-state is smaller, dynamic response time is shorter, ability to filter harmonics and reactive power compensation are very effective. Moreover, the proposed control method has online control capability very well. Simulation and experimental results shown the feasibility and validity of the proposed control method. 


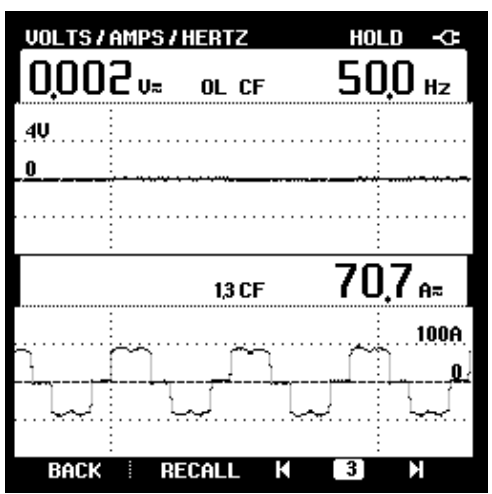

(a)

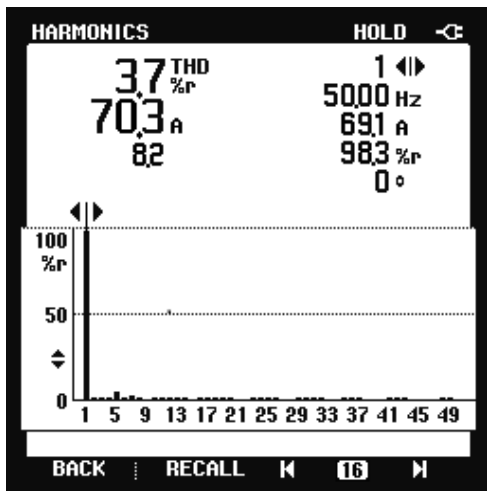

(d)

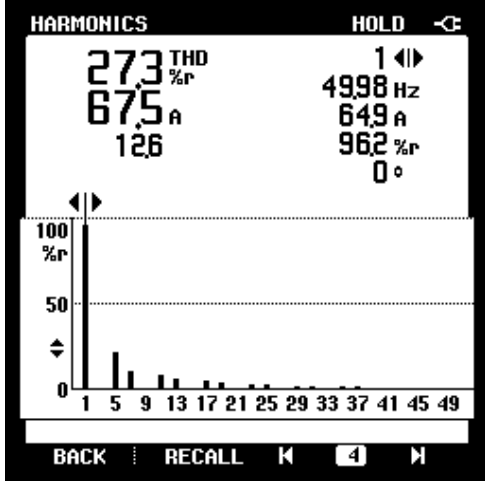

(b)

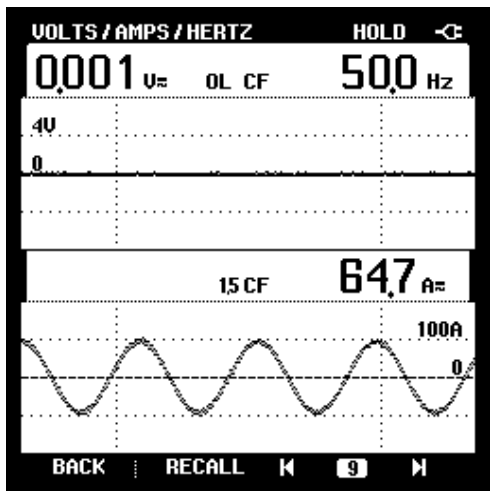

(e)

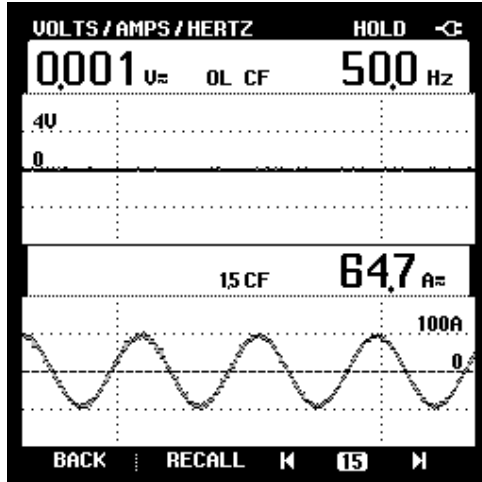

(c)

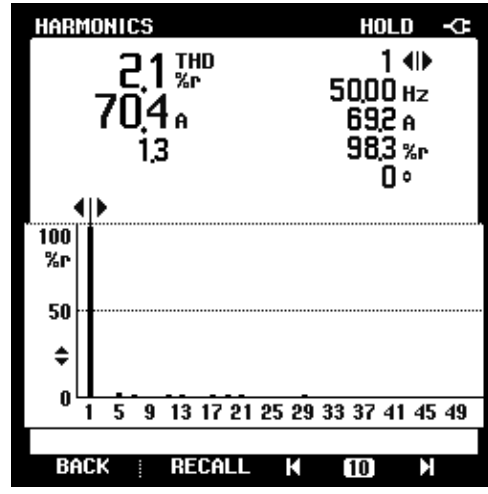

(f)

Fig. 9. Experimental results before the load is changed, (a) - waveform of the load current, (b) - frequency spectrum of the load current, (c) - waveform of the source current with the single fuzzy logic method, (d) - frequency spectrum of the source current with the single fuzzy logic method, (e) - waveform of the source current with the proposed control method, (f) - frequency spectrum of the source current with the proposed method

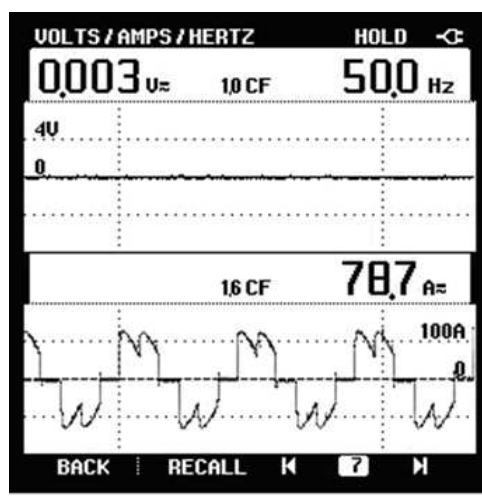

(a)

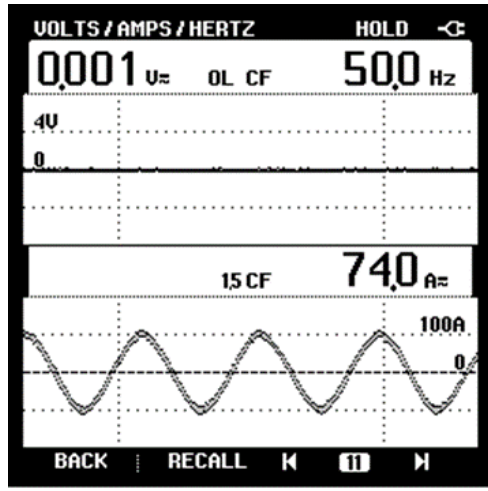

(d)

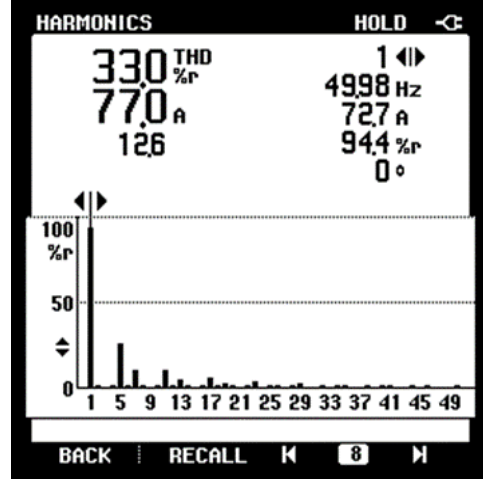

(b)

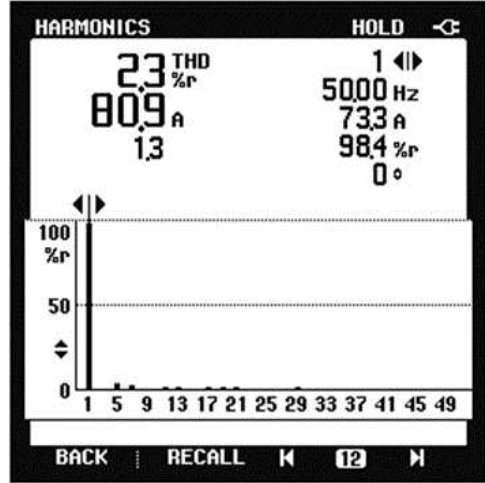

(e)

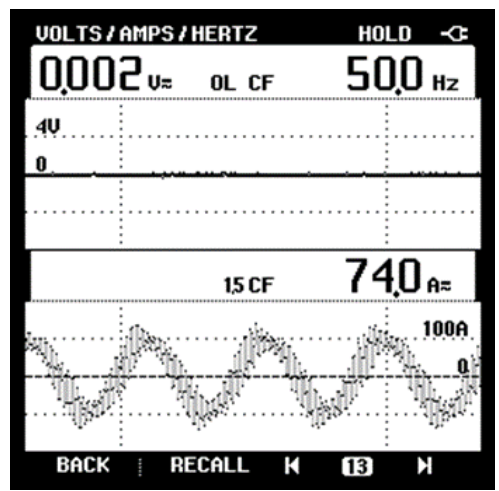

(c)

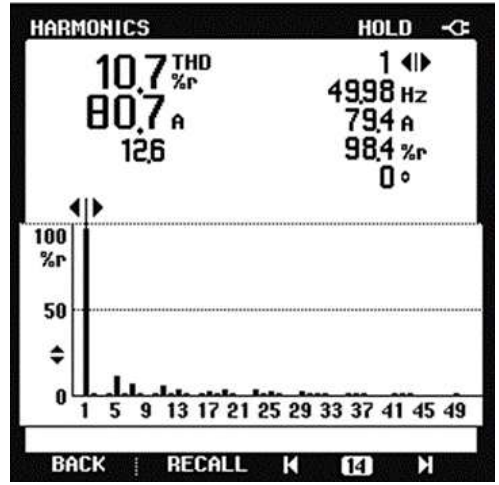

(f)

Fig. 10. Experimental results after the load is changed, (a) - waveform of the load current, (b) - frequency spectrum of the load current, (c) - waveform of the source current with the single fuzzy logic method, (d) - frequency spectrum of the source current with the single fuzzy logic method, (e) - waveform of the source current with the proposed control method, (f) - frequency spectrum of the 


\section{REFERENCES}

[1] ERTAY, M. M.-TOSUN, S.-ZENGIN, A.: Simulated Annealing Based Passive Power Filter Design for a Medium Voltage Power System, International Symposium on Innovations in Intelligent Systems and Applications (INISTA), 2012, pp. 1-5.

[2] JUNPENG, J.-ZENG, G.-LIU, H.-LUO, L.-ZHANG, J. : Research on Selection Method of Passive Power Filter Topologies, 7th International Power Electronics and Motion Control Conference (IPEMC), 2012, pp. 2844-2848.

[3] SU, C. L.-HONG, C.: Design of Passive Harmonic Filters to Enhance Power Quality and Energy Efficiency in Ship Power Systems, 49th IEEE/IAS Industrial \& Commercial Power Systems Technical Conf (I\&CPS), 2013, pp. 1-8.

[4] DARYASAFAR, N.-HAMIDI, S.-SHAHRYARI, G. R. : Design and Analysis of an Ultra-Wideband Band-Notched BandPass Filter, Journal of Electrical Engineering 66 No. 2 (2015), 113-116.

[5] GE, J. J.-ZHAO, Z. M.-LI, J. J. : Backstepping Control for Active Power Filter with LCL Filter, 2nd IET Renewable Power Generation Conference (RPG), 2013, pp. 1-4.

[6] MAhajAn, V.-AGARWAL, P.—GUPTA, H. O. : Simulation of Shunt Active Power Filter Using Instantaneous Power Theory, IEEE Fifth Power India Conference, 2012, pp. 1-5.

[7] CHOI, W. H.-LAM, C. S.-WONG, M. C.-HAN, Y. D. : Analysis of DC-Link Voltage Controls in Three-Phase Four-Wire Hybrid Active Power Filters, IEEE Transactions on Power Electronics 28 No. 5 (2013), 2180-2191.

[8] PANDA, G.-DASH, S. K.-SAHOO, N. : Comparative Performance Analysis of Shunt Active Power Filter and Hybrid Active Power Filter using FPGA-based Hysteresis Current Controller, IEEE 5th India International Conference on Power Electronics (IICPE), 2012, pp. 1-6.

[9] CHAU, M. T.-LUO, A.-CHAU, V. B.: PID-Fuzzy Control Method with Time Delay Compensation for Hybrid Active Power Filter with Injection Circuit, International Journal of Computer Applications 36 No. 7 (2011), 15-21.

[10] VESELÝ, V.-ILKA, A.: Robust Gain-Scheduled Pid Controller Design For Uncertain Lpv Systems, Journal of Electrical Engineering 66 No. 1 (2015), 19-25.

[11] SURESH, Y.-PANDA, A. K.-SURESH, M. : Real-Time Implementation of Adaptive Fuzzy Hysteresis-Band Current Control Technique for Shunt Active Power Filter, IET Power Electronics 5 No. 7 (2012), 1188-1195.

[12] OGBukA, C.-NWOSU, C.-AGU, M. : A Fast Hysteresis Current-Controlled Permanent Magnet Synchronous Motor Drive Based On Field Orientation, Journal of Electrical Engineering 67 No. 2 (2016), 69-77.

[13] LUO, A.-SHUAI, Z. K.-ZHU, W.-FAN, R. X.-TU, C. M. : Development of Hybrid Active Power Filter Based on the Adap- tive Fuzzy Dividing Frequency-Control Method, IEEE transactions on power delivery 24 No. 1 (2009), 424-432.

[14] ESKANDARIAN, N.-BEROMI, Y. A.-FARHANGI, S. : Improvement of Dynamic Behavior of Shunt Active Power Filter Using Fuzzy Instantaneous Power Theory, Journal of Power Electronics 14 No. 6 (2014), 1303-1313.

[15] WEI, C.-QIN, L.-LUT. J.-RONG, P. H.-ZHAO, Y. Q. : Method of Event Detection Based on Dynamic Hybrid Fuzzy Logic System, International Conference on Intelligent Computation Technology and Automation, 2010, pp. 661-663.

[16] LIU, W.-ZHANG, D. W.: Study on a Series Hybrid Active Power Filter Based on Novel Fuzzy Immune PID Controller, International Conference on Measurement, Information and Control (MIC), 2012, pp. 520-523.

17] HELAL, A. A.-ZAKZOUK, N. E.-DESOUKY, Y. G. : Fuzzy Logic Controller Shunt Active Power Filter for Three-phase Four-wire Systems with Balanced and Unbalanced Loads, World Academy of Science, Engineering and Technology 58 (2009), 621-626.

18] FEI, J. T.-ZHE, W.-LU, X. C.-DENG, L. H. : Adaptive RBF Neural Network Control Based on Sliding Mode Controller for Active Power Filter, 32nd Chinese Control Conference (CCC), 2013, pp. 3288-3293.

[19] KUMAR, A. S.-RAJ, P. A. : Neural Learning Algorithm Based Power Quality Enhancement for Three Phase Three Wire Distribution System Utilizing Shunt Active Power Filter Strategy, International Conference on Power and Energy Systems (ICPS), 2011, pp. 1-6.

[20] MARTINEK, R.-KELNAR, M.-VANUS, J.-BILIK, P.ZIDEK, J.: A Robust Approach for Acoustic Noise Suppression In Speech Using ANFIS, Journal of Electrical Engineering 66 No. 6 (2015), 301-310.

[21] GHAZANFARPOUR, B.-RADZI, M. A. M.-MARIUN, N.SHOORANGIZ, R. : Adaptive Unified Neural Network for Dynamic Power Quality Compensation, IEEE 7th International Power Engineering and Optimization Conference (PEOCO), 2013, pp. 114-118.

Received 4 February 2016

Minh Thuyen Chau was born in Binh Dinh, Vietnam, in 1977. He received his BS and MS from the Da Nang University of Technology, Da Nang, Vietnam, and the University of Technical Education Ho Chi Minh City, Ho Chi Minh City, Vietnam, in 2001 and 2005, respectively, and $\mathrm{PhD}$ from $\mathrm{Hu}-$ nan University, Changsha, China, in 2012. Since 2004, he has been a Lecturer at Faculty of Electrical Engineering ;Industrial University of Ho Chi Minh City, Vietnam. His current research interests include electric power savings, reactive power compensation, active power filters and renewable energy. 